\title{
Parents' Internet use for information about HPV vaccine
}

\author{
Annie-Laurie McRee, DrPH ${ }^{a}$, Paul L. Reiter, PhD ${ }^{b, c}$, and Noel T. Brewer, PhD ${ }^{a, d}$ \\ aGillings School of Global Public Health, University of North Carolina at Chapel Hill, 325 Rosenau \\ Hall CB 7440, Chapel Hill, NC 27599-7440, USA \\ bDivision of Cancer Prevention and Control, College of Medicine, The Ohio State University, \\ Columbus, $\mathrm{OH} 43201$, USA \\ ${ }^{\circ}$ Comprehensive Cancer Center, The Ohio State University, Columbus, OH 43210, USA \\ dLineberger Comprehensive Cancer Center, University of North Carolina at Chapel Hill, CB 7295, \\ University of North Carolina at Chapel Hill, 450 West Drive, Chapel Hill, NC 27599-7295, USA
}

\begin{abstract}
Purpose-The Internet is an increasingly common source of health-related information. We sought to examine associations between parents' Internet information-seeking and their knowledge, attitudes and beliefs about human papillomavirus (HPV) vaccine.
\end{abstract}

Methods-We interviewed parents within a year after approval of HPV vaccine for females and males. Participants were North Carolina parents with daughters ages 10-18 surveyed by telephone in Fall 2007 ( $n=773)$; and a national sample of parents with sons ages 11-17 surveyed online in Fall 2010 ( $n=115)$. We used multivariate regression to examine associations of past and intended Internet seeking for HPV vaccine information with knowledge and health belief model-related constructs.

Results-Among parents of daughters, having heard of HPV vaccine through the Internet (8\%) was associated with higher HPV knowledge, perceived likelihood of HPV, and vaccination willingness, and with receiving a doctor's recommendation. It was also associated with lower perceived vaccine harms, uncertainty, and anticipated regret. Parents of sons who heard of HPV vaccine through the Internet (10\%) perceived greater barriers to vaccination than parents who learned about HPV vaccine for males through other sources. Intended future Internet informationseeking among parents of daughters (69\%) was more likely if they perceived a lower likelihood that their daughters would get HPV if they were vaccinated (all $p<.05$ ).

Conclusions-Our findings suggest a positive influence of accessing information on the Internet about HPV vaccine. It was associated with higher knowledge and mostly positive parental attitudes and beliefs.

\section{Keywords}

HPV vaccine; adolescent health; Internet; health belief model

Correspondence and requests for reprints should be sent to: Annie-Laurie McRee, DrPH, Gillings School of Global Public Health, University of North Carolina at Chapel Hill, Department of Health Behavior and Health Education, 325 Rosenau Hall, CB 7440, Chapel Hill, NC 27599-7440, Tel: 919-843-3105, Fax: 919-966-2921, almcree@email.unc.edu.

Publisher's Disclaimer: This is a PDF file of an unedited manuscript that has been accepted for publication. As a service to our customers we are providing this early version of the manuscript. The manuscript will undergo copyediting, typesetting, and review of the resulting proof before it is published in its final citable form. Please note that during the production process errors may be discovered which could affect the content, and all legal disclaimers that apply to the journal pertain. 


\section{Introduction}

The Internet is an increasingly common source of health-related information. On the one hand, the Internet can provide high quality information that is widely disseminated. It has become the "go to" resource for health information for many people. On the other hand, while the quality of the information is often high, it can vary widely. Sites often have missing or incomplete information [1] or, more rarely, inaccurate information [2]. Furthermore, the Internet may draw people who perceive that they are unhealthy [3, 4], who have serious or stigmatized health needs $[5,6]$, or who experience barriers to traditional care [5].

All of these issues may be at hand with human papillomavirus (HPV) vaccine information on the Internet [7-9]. High quality information about HPV vaccine is available from public agencies, but some sites, especially those opposing HPV vaccine, provide information that is of more mixed quality or presented in a misleading fashion $[8,9]$. Online news stories reveal a similar mix of quality and gaps [7]. Though the Internet is an important source of information for parents about HPV vaccine [10], we know of no research examining whether obtaining information about HPV vaccine on the Internet is associated with better or poorer knowledge. Low quality information on the web might engender poor knowledge, but then it could be that exposure to the large store of information across many sites instead increases knowledge.

Internet use might also affect key attitudes and beliefs which, in turn, may shape parents' intentions to get their children vaccinated against HPV [11, 12]. The health belief model [13], a widely used theoretical model of health behavior, provides a practical conceptual basis for this work. As we have described the relevance of this conceptualization to HPV vaccination previously [11, 14], we summarize it here only in brief. The health belief model suggests that people are more likely to engage in health-related behaviors, like getting vaccinated, if they believe a threat is likely (perceived risk of HPV infection) or severe (perceived severity of the consequences of HPV infection), if they perceive the preventive effort is safe (perceived harms from HPV vaccine) and effective (perceived benefits/ effectiveness of HPV vaccine), and if a doctor recommends it (cue to action). We also sought to understand how health belief model constructs might influence subsequent Internet searching, as this is a kind of health behavior and a logical consequence of the change in such beliefs $[15,16]$.

Thus, our paper has three goals. First, we examined whether Internet use was associated with better or poorer HPV knowledge. Second, we examined whether Internet use was associated with beliefs about HPV-related diseases and HPV vaccine that prompt vaccination. Finally, we examined whether these beliefs prompted intentions to gather information on the web. To address these questions, we analyzed data from two large studies of parents of children in the recommended age range to receive HPV vaccine.

\section{Materials and Methods}

\subsection{Study Design}

We used data from 2 of our research studies, the Carolina HPV Immunization Measurement and Evaluation (CHIME) parent study and the HPV Immunization in Sons (HIS) study. This allowed us to gain unique insight into the online information-seeking behaviors of parents regarding HPV vaccine about a year after the vaccine was licensed for females (licensed in 2006 [17]) and males (licensed in 2009 [18]). The CHIME and HIS studies are described in detail elsewhere $[10,19,20]$ and briefly here. The Institutional Review Board at the University of North Carolina at Chapel Hill approved both studies. 
The CHIME study examined HPV vaccine acceptability and uptake among parents of adolescent daughters. We contacted a probability sample of households in areas of North Carolina with elevated cervical cancer rates. Trained personnel used computer-assisted telephone interviewing equipment to conduct interviews with parents of females ages 10 to 18. Of 1220 eligible parents contacted, 889 (73\%) completed interviews between July and October 2007. The present analysis used data from parents who were aware of HPV vaccine at the time of the study $(n=733)$.

The HIS Study examined parents' attitudes and beliefs about HPV vaccination for their adolescent sons. We surveyed parents with sons ages 11-17 who were members of an existing national panel [21]. The panel consists of a probability-based sample of US households constructed using list-assisted, random-digit dialing and address-based sampling. In August and September 2010, we invited parents to participate in our online survey. Of 1195 parents invited to participate, 752 responded. Among parents who responded, $73 \%$ $(n=547)$ were eligible and completed a survey. The present analysis used data from parents who were aware at the time of the study that HPV vaccine could be given to males $(n=115)$.

\subsection{Measures}

Full surveys for both studies are available at http://www.unc.edu/ ntbrewer/hpv.htm. The primary variables of interest were parents' having heard about HPV vaccine through the Internet (past Internet use; assessed on both surveys) and parent report that they would use the Internet if they "had a strong need to get information about the HPV vaccine" (future Internet information-seeking; assessed on the CHIME survey only) (both yes/no). The CHIME survey assessed parents' HPV knowledge. Surveys included key health belief model constructs: perceived likelihood and severity of HPV infection, perceived safety and effectiveness of HPV vaccination, perceived barriers to action, and doctor's recommendation. The surveys assessed anticipated regret, a risk measure that adds an affective dimension; while it is not explicitly in the health belief model, it plays a large role in vaccine decisions $[19,22]$. They assessed anticipated vaccination regret (if they got their child vaccinated and their child then experienced a negative outcome) and anticipated inaction regret (if they did not get their child vaccinated and their child later developed an HPV infection). The surveys also examined HPV vaccination intentions, vaccine uptake, and sociodemographic characteristics.

\subsection{Data Analysis}

We examined associations between past Internet use (independent variable) and HPV vaccine-related outcomes with linear regression (continuous outcomes) and logistic regression (dichotomous outcomes). We then assessed correlates of future Internet information-seeking (dependent variable) with logistic regression. Because bivariate and multivariate models showed a similar pattern of findings, we report only multivariate findings which controlled for sociodemographic variables associated $(p<.05)$ in bivariate models. Models of past Internet use controlled for parent's gender, age, race/ethnicity, education, household income, urbanicity, and child's age. The model of future Internet information-seeking controlled for parent's race/ethnicity, education, and household income. Analyses used Stata SE version 10.0 (Statacorp, College Station, TX) and all statistical tests were two-tailed with a critical alpha of .05 .

\section{Results}

\subsection{Demographic Characteristics}

In the CHIME study of parents of adolescent girls, most parents were female (96\%; Table 1), older than 45 years of age (72\%), non-Hispanic white (74\%) or non-Hispanic Black 
(20\%), and had at least some college education (82\%). Parents included in our analyses (aware of HPV vaccine prior to the study) were more likely to be female, be non-Hispanic white, have at least some college education, and have a household income of $\$ 60,000$ or over, compared to parents who were not aware (all $p<.05$ ). For the HIS Study, most parents of adolescent boys were female (64\%), younger than 45 years of age (64\%), non-Hispanic White $(69 \%)$, and living in urban areas ( $81 \%)$. Parents who were aware of HPV vaccine for males had similar sociodemographic characteristics to those not aware (all $p>.05$ ). Few daughters $(13 \%)$ or sons $(8 \%)$ had received any doses of the vaccine at the time of the surveys.

\subsection{Past Internet Use}

Among parents of daughters who were already aware of HPV vaccine at the time of CHIME survey, 21\% (154/773) reported having heard about HPV vaccine through the Internet. In multivariate analyses, parents who reported the Internet as a past source of information had greater knowledge about HPV (knowledge scale mean $=67 \%$ vs. $57 \%$ correct, $\beta=0.17$, Table 2). Specifically, a higher proportion of these parents knew that HPV: can cause cervical cancer or genital warts, is a sexually transmitted disease (STD), is relatively common, and can cause abnormal pap smears. Parents who heard about HPV vaccine through the Internet perceived greater likelihood that their daughters would get HPV if they do not get vaccinated $(\beta=0.08)$ than parents who heard about HPV vaccine through other sources (Table 3). These parents also perceived fewer vaccine harms $(\beta=-0.12)$, had less uncertainty about HPV vaccine $(\beta=-0.14)$, and anticipated less regret if their daughters became sexually active as a result of getting vaccinated $(\beta=-0.09)$. Parents who reported having heard about HPV vaccine through the Internet also had greater willingness to get their daughter vaccinated against HPV $(\beta=0.08)$. More parents who the Internet as a past source of information about HPV vaccine reported receiving a doctor's recommendation to get their daughter vaccinated (35\% vs $21 \%$; OR=1.97; 95\% CI: 1.33-2.93).

Among parents of sons who were already aware that HPV vaccine could be given to males at the time of the HIS survey, 17\% (19/115) reported having heard about HPV vaccine through the Internet. In multivariate analyses, parents who reported the Internet as a source of information perceived greater barriers to vaccination than parents who learned about HPV vaccine for males through other sources $(\beta=0.23$; Table 4$)$. Past Internet use was not associated with parents' willingness to have their son receive HPV vaccine. Because few parents who heard about HPV vaccine for males through the Internet also reported receiving a doctor's recommendation to get their son vaccinated $(n=3)$, we were unable to assess this association among parents of sons.

\subsection{Future Internet Information-Seeking}

Most parents in the CHIME study reported that they would go to the Internet if they had a strong need for information about HPV vaccine (69\%; 505/773). In multivariate analyses, parents were more likely to report that they would go to the Internet as a source of information if they perceived lower likelihood that their daughters would get HPV if they received HPV vaccine (OR=0.67; 95\% CI: 0.48-0.92; Table 5). Parents' vaccination willingness was not associated with their report of intended future Internet informationseeking.

\section{Discussion}

4.1.1 Findings-In this study, we found that accessing information on the Internet was associated with higher knowledge and mostly positive parental perceptions about HPV vaccine. Consistent with previous research that found greater health knowledge among those 
who search the Internet for information [23], parents in the CHIME study who heard about HPV vaccine through the Internet had greater knowledge about HPV. Individuals who search for information on the Internet tend to be more health-oriented [24], so it is unclear whether or not parents in this study would have greater HPV knowledge anyway.

Past Internet use was also associated with several constructs from the health belief model which we previously reported were associated with HPV vaccine acceptability $[11,12]$ and uptake [22]. Compared to parents who heard about HPV vaccine through other sources, parents who heard about it through the Internet had more positive HPV vaccine attitudes and beliefs about the vaccine and were more likely to report receiving a doctor's recommendation to get their daughter vaccinated. Unlike previous studies suggesting the Internet could contribute to parental refusal of vaccination generally [25], we found that parents' past Internet use was associated with greater willingness to get their daughters vaccinated against HPV. However, intent does not always lead to behavior and, in other research (including analyses using CHIME data), hearing about HPV vaccine through the Internet was not associated with vaccine uptake $[10,26]$.

We also found that the Internet was a highly preferred source among parents with adolescent daughters for future information-seeking about HPV vaccine. This was generally true regardless of parents' current beliefs and attitudes about the vaccine. With parents having such strong preferences to get future information from the Internet, it becomes important that they are able to easily locate valid, clear, and complete online information about HPV and HPV vaccine [7].

In contrast to the generally positive picture of Internet information we found among parents of daughters, we found that having heard about HPV vaccine through the Internet was associated with greater perceived barriers to vaccination among parents of sons. The reason for this positive association is unclear from our data. It may be that parents learned about actual barriers to HPV vaccination for males through the Internet. For example, the Advisory Committee on Immunization Practices (ACIP) provided only a permissive recommendation for HPV vaccine for males [27], as compared to the routine recommendation provided for females [28]. The weaker permissive recommendation could affect insurance coverage of the vaccine for male [29] and healthcare provider recommendations, both of which may influence parents' vaccination decisions. The heightened perception of barriers to vaccination among parents who heard about HPV vaccine through the Internet could also reflect a lack of information available about HPV vaccine for males. Previous research has found that there are often gaps in information available through the Internet [1] and HPV vaccine for males has received far less media and advertising attention than HPV vaccine for females received at a similar point after licensure $[7,30]$.

\subsection{Strengths and Limitations}

Strengths of this analysis include the use of data from 2 complementary studies and information on multiple HPV vaccine attitudes and beliefs. However, our study also has several limitations including the cross-sectional nature of both study designs that precludes making causal inferences about the relationship between Internet information and vaccine attitudes, beliefs, and intentions. The measures of past Internet use and future Internet information-seeking relied on self-report and did not assess information source or quality. Surveys included different scale measures for some attitudes and beliefs which may have affected associations with Internet use. As few parents of sons were aware at the time of the survey that HPV vaccine could be given to males, we had limited power to detect differences in this sample. Making comparisons between findings from parents of daughters and parents of sons requires care as data came from different samples (regional versus 
national, different years of data collection) that could have been exposed to different messages about HPV vaccine. However, an important similarity is that both studies collected data about a year post-vaccine licensure.

\subsection{Conclusion}

Our findings suggest that the Internet is not only an important source of information about HPV vaccine for parents of adolescents, but that it can also be a positive one. Future research is needed to understand how to capitalize on the Internet as a source of information and monitor temporal trends in parents' use of the Internet for HPV vaccine information as time since vaccine licensure increases. This may be particularly important for parents with adolescent sons, as more information on HPV vaccination and males may become available.

\section{References}

1. Berland GK, Elliott MN, Morales LS, Algazy JI, Kravitz RL, Broder MS, et al. Health information on the Internet: accessibility, quality, and readability in English and Spanish. JAMA. 2001; 285(20): 2612-21. [PubMed: 11368735]

2. Eysenbach G, Powell J, Kuss O, Sa E. Empirical studies assessing the quality of health information for consumers on the World Wide Web: A systematic review. JAMA. 2002; 287(20):2691-270. [PubMed: 12020305]

3. Shim JW. The use of e-health information and health behavior change: The role of perceived health status and types of e-health information use. The Open Communication Journal. 2008; 2:156-63.

4. Houston KT, Allison JJ. Users of Internet health information: Differences by health status. J of Medical Internet Research. 2002; 4(2)

5. Bundorf MK, Wagner TH, Singer SJ, Baker LC. Who searches the internet for health information? Health Serv Res. 2006; 41(3):819-36. [PubMed: 16704514]

6. Berger M, Wagner TH, Baker LC. Internet use and stigmatized illness. Soc Sci Med. 2005; 61(8): 1821-2827. [PubMed: 16029778]

7. Habel MA, Liddon N, Stryker JE. The HPV vaccine: A content analysis of online news stories. J Women's Health. 2009; 18(3):401-7.

8. Keelan J, Pavri V, Balakrishnan R, Wilson K. An analysis of the human papillomavirus vaccine debate on MySpace blogs. Vaccine. 2010; 28:1535-40. [PubMed: 20003922]

9. Tozzi AE, Buonuomo PS, Ciofi degli Atti ML, Carloni E, Meloni M, Gamba F. Comparison of quality of internet pages on human papillomavirus immunization in Italian and in English. $\mathrm{J}$ Adolesc Health. 2010; 46(1):83-9. [PubMed: 20123262]

10. Hughes J, Cates J, Liddon N, Smith JS, Gottlieb SL, Brewer NT. Disparities in how parents are hearing about the HPV vaccine. Cancer Epid Biomarkers Prev. 2009; 18(2):363-72.

11. Brewer NT, Fazekas KI. Predictors of HPV vaccine acceptability: A theory-informed, systematic review. Prev Med. 2007; 45(2-3):107-14. [PubMed: 17628649]

12. McRee AL, Brewer NT, Reiter PL, Gottlieb S, Smith JS. The Carolina HPV Immunization Attitudes and Beliefs Scale (CHIAS): Scale development and associations with intentions to vaccinatw. Sex Transm Dis. 2010; 37(4):234-9.

13. Becker MH. The health belief model and personal health behavior. Health Educ Monogr. 1974; 2:324-508.

14. Reiter PL, Brewer NT, Gottlieb SL, McRee AL, Smith JS. Parents' health beliefs and HPV vaccination of their adolescent daughters. Soc Sci Med. 2009; 69(3):475-80. [PubMed: 19540642]

15. Brewer NT, Weinstein ND, Cuite CL, Herrington JE. Risk perceptions and their relation to risk behavior. Ann Behav Med. 2004; 27(2):125-30. [PubMed: 15026296]

16. Brewer NT, Weinstein ND, Cuite CL, Herrington JE. Risk compensation and vaccination: Can getting vaccinated cause people to engage in risky behaviors? Ann of Behavl Med. 2007; 34:95-9.

17. US Food and Drug Administration. FDA licenses new vaccine for prevention of cervical cancer and other diseases in females caused by human papillomavirus [press release]. 2006. [updated June 8; cited 2009 Aug 20]; Available from: 
http://www.fda.gov.libproxy.lib.unc.edu/NewsEvents/Newsroom/PressAnnouncements/2006/ ucm108666.htm

18. U.S. Food and Drug Administration. FDA approves new indication for Gardasil to prevent genital warts in men and boys. [Internet]. 2009. [cited 2009 Nov 6]; Available from: http://www.fda.gov/NewsEvents/Newsroom/PressAnnouncements/ucm187003.htm

19. Ziarnowski KL, Brewer NT, Weber B. Present choices, future outcomes: Anticipated regret and HPV vaccination. Prev Med. 2009; 48(5):411-4. [PubMed: 18996144]

20. Reiter, PL.; McRee, AL.; Kadis, JA.; Brewer, NT. HPV Vaccine and Adolescent Males Vaccine. In press

21. Dennis, JM. Description of within-panel survey sampling methodology: the Knowledge Networks approach. 2009. [cited 2009 July 7]; Available from:

http://knowledgenetwoks.com/ganp/docs/KN\%20Within-Panel\%20Survey20Sampling $\% 20$ Methodology.pdf

22. Brewer NT, Gottlieb SL, Reiter PL, McRee AL, Liddon N, Markowitz L, et al. Longitudinal predictors of human papillomavirus vaccine initiation among adolescent girls in a high-risk geographic area. Sex Transm Dis. 2011 Mar; 38(3):197-204. [PubMed: 20838362]

23. Brewer, NT. The impact of Internet use on health cognitions and health behavior. In: Haugtvedt, CP.; Machleit, KM.; Yalch, R., editors. Online Consumer Psychology: Understanding and Influencing Consumer Behavior in the Virtual World. Mahwah, NJ: Lawrence Erlbaum; 2005. p. 433-53.

24. Dutta-Bergman MJ. Health attitudes, health cognitions, and health behaviors among Internet health information seekers: population-based survey. J Med Internet Res. 2004; 6(2):e15. [PubMed: 15249264]

25. Zimmerman RK, Wolfe RM, Fox DE, Fox JR, Nowalk MP, Troy JA, et al. Vaccine criticism on the World Wide Web. J Med Internet Res. 2005; 7(2):e17. [PubMed: 15998608]

26. Cates JR, Shafer A, Carpentier FD, Reiter PL, McRee AL, Brewer NT, et al. How parents hear about the HPV vaccine: Implications for uptake. J Adolesc Health. 2010; 47(2):305-8. [PubMed: 20708571]

27. Centers for Disease Control and Prevention (CDC). FDA licensure of quadrivalent human papillomavirus vaccine (HPV4, Gardasil) for use in males and guidance from the Advisory Committee on Immunization Practices (ACIP). MMWR Morb Mortal Wkly Rep. 2010; 59(20): 630-2. [PubMed: 20508594]

28. Markowitz LE, Dunne EF, Saraiya M, Lawson HW, Chesson H, Unger ER. Quadrivalent human papillomavirus vaccine: Recommendations of the Advisory Committee on Immunization Practices (ACIP). MMWR Morb Mortal Wkly Rep. 2007; 56:1-24. [PubMed: 17218934]

29. Haupt, RM.; Sylvester, GC. HPV disease in males and vaccination: Implications and opportunities for pediatricians. Infectious Diseases in Children [serial on the Internet]. 2010. Available from: http://www.pediatricsupersite.com/view.aspx?rid=66396

30. Calloway C, Jorgensen CM, Saraiya M, Tsui J. A content analysis of news coverage of the HPV vaccine by US newspapers, January 2002-June 2005. J Women's Health (Larchmt). 2006; 15(7): 803-9. 


\section{Highlights}

- We used data from 2 studies with parents of adolescents.

- We examined parents' Internet information-seeking and HPV vaccine attitudes.

- Internet use was associated with higher knowledge and mostly positive perceptions. 
Table 1

Description of parents and their children

\begin{tabular}{|c|c|c|}
\hline & $\frac{\text { CHIME, } n=733}{n(\%)}$ & $\frac{\text { HIS, } n=115}{n(\%)}$ \\
\hline \multicolumn{3}{|l|}{ Parent Characteristics } \\
\hline \multicolumn{3}{|l|}{ Gender } \\
\hline Female & $703(95.9)$ & $74(64.4)$ \\
\hline Male & $30(4.1)$ & $41(35.7)$ \\
\hline \multicolumn{3}{|l|}{ Age } \\
\hline$<45$ years & $207(28.2)$ & $73(63.5)$ \\
\hline$\geq 45$ years & $526(71.8)$ & $42(36.5)$ \\
\hline \multicolumn{3}{|l|}{ Race / Ethnicity } \\
\hline Non-Hispanic white & $544(74.2)$ & $79(68.7)$ \\
\hline Non-Hispanic Black & $148(20.2)$ & $10(8.7)$ \\
\hline Hispanic or other race/ethnicity & $41(5.6)$ & $26(22.6)$ \\
\hline \multicolumn{3}{|l|}{ Education } \\
\hline High school degree or less & $131(17.9)$ & 48 (41.7) \\
\hline Some college or more & $602(82.1)$ & $67(58.3)$ \\
\hline \multicolumn{3}{|l|}{ Household characteristics } \\
\hline \multicolumn{3}{|l|}{ Annual household income } \\
\hline$<\$ 60,000$ & $324(44.2)$ & $50(43.5)$ \\
\hline $2 \$ 60,000$ & $409(55.8)$ & $65(56.5)$ \\
\hline \multicolumn{3}{|l|}{ Urbanicity } \\
\hline Urban & $369(50.3)$ & $93(80.9)$ \\
\hline Rural & $364(49.7)$ & $22(19.1)$ \\
\hline \multicolumn{3}{|l|}{ Child characteristics } \\
\hline \multicolumn{3}{|l|}{ Gender } \\
\hline Female & $733(100)$ & $0(0.0)$ \\
\hline Male & $0(0.0)$ & $115(100)$ \\
\hline Age, mean (SD) & $14.7(3.5)$ & $13.9(2.2)$ \\
\hline Received at least 1 dose of HPV vaccine & $97(13.2)$ & $9(7.8)$ \\
\hline
\end{tabular}

Note. Percentages may not total $100 \%$ due to rounding. 
Table 2

Past Internet use as a correlate of HPV knowledge among parents of daughters (CHIME), $n=733$

\begin{tabular}{|c|c|c|c|}
\hline & $\begin{array}{c}\text { No } \\
\text { Mean (SD) }\end{array}$ & $\begin{array}{c}\text { Yes } \\
\text { Mean (SD) }\end{array}$ & $\begin{array}{l}\text { Multivariate } \\
\text { OR }(95 \% \mathrm{CI})\end{array}$ \\
\hline HPV knowledge scale ${ }^{a, b}$ & $0.57(0.20)$ & $0.67(0.16)$ & $0.17^{* *}$ \\
\hline HPV can cause cervical cancer ${ }^{c}$ & $0.82(0.39)$ & $0.90(0.30)$ & $1.98(1.11-3.51)^{*}$ \\
\hline HPV can cause genital warts ${ }^{c}$ & $0.41(0.49)$ & $0.52(0.50)$ & $1.52(1.05-2.16)^{*}$ \\
\hline $\mathrm{HPV}$ is a sexually transmitted disease ${ }^{c}$ & $0.54(0.50)$ & $0.69(0.46)$ & $1.75(1.89-2.59)^{*}$ \\
\hline $\mathrm{HPV}$ infection is rare $e^{c, d}$ & $0.71(0.46)$ & $0.88(0.33)$ & $2.73(1.61-4.60)^{* * *}$ \\
\hline $\mathrm{HPV}$ can cause abnormal paps ${ }^{c}$ & $0.84(0.37)$ & $0.91(0.29)$ & $1.91(1.05-3.47)^{*}$ \\
\hline
\end{tabular}

Note. Multivariate models control for parent gender, age, race/ethnicity, education, household income, urbanicity, and child's age which were associated with HPV vaccine knowledge, attitudes, beliefs, or intentions in bivariate analyses $(p<.05)$. HPV= Human papillomavirus; $\mathrm{SD}=$ standard deviation

${ }^{a}$ Proportion of correct responses to 5 items about HPV infection.

${ }^{b}$ Standardized beta coefficient $(\beta)$ from linear regression model.

${ }^{c}$ Proportion of correct responses to item.

$d_{\text {Item was reverse-coded to indicate correct response. }}$

* $p<0.05$,

** $p<0.001$ 
Table 3

Past Internet use as a correlate of HPV vaccine attitudes and beliefs among parents of daughters (CHIME), $\underline{n=733}$

\begin{tabular}{|c|c|c|c|}
\hline & $\begin{array}{c}\text { No } \\
\text { Mean (SD) }\end{array}$ & $\begin{array}{c}\text { Yes } \\
\text { Mean (SD) }\end{array}$ & $\begin{array}{c}\text { Multivariate } \\
\beta\end{array}$ \\
\hline Perceived likelihood of HPV if child does not receive HPV vaccine ${ }^{a}$ & $2.49(0.72)$ & $2.62(0.66)$ & $0.08^{*}$ \\
\hline Perceived likelihood of HPV if child receives HPV vaccine ${ }^{a}$ & $2.04(0.53)$ & $2.07(0.53)$ & 0.01 \\
\hline Perceived severity of cervical cancer ${ }^{b}$ & $\underline{3.70(0.58)}$ & $\underline{3.77(0.46)}$ & $\underline{0.03}$ \\
\hline Anticipated regret if child receives HPV vaccine ${ }^{c}$ & $2.70(1.25)$ & $2.41(1.24)$ & $-0.09^{*}$ \\
\hline Anticipated regret if child does not receive HPV vaccine ${ }^{c}$ & $3.62(0.77)$ & $3.72(0.68)$ & 0.06 \\
\hline Uncertainty about HPV vaccine ${ }^{d}$ & $2.74(0.79)$ & $2.45(0.83)$ & $-0.14^{* *}$ \\
\hline Perceived harms of HPV vaccine $e^{e}$ & $2.14(0.55)$ & $2.01(0.53)$ & $-0.12^{* *}$ \\
\hline Perceived barriers to getting child HPV vaccine ${ }^{f}$ & $1.57(0.57)$ & $1.51(0.53)$ & -0.04 \\
\hline Perceived effectiveness of HPV vaccine $g$ & $2.50(0.62)$ & $2.58(0.64)$ & 0.05 \\
\hline Willingness to get child vaccinated against $\mathrm{HPV}^{h}$ & $2.89(0.99)$ & $3.03(0.96)$ & $0.08^{*}$ \\
\hline
\end{tabular}

Note. $\beta$ s represent standardized beta coefficients from multivariate models controlling for parent gender, age, race/ethnicity, education, household income, urbanicity, and child's age which were associated with HPV vaccine knowledge, attitudes, beliefs, or intentions in bivariate analyses ( $p<$. 05). $\mathrm{HPV}=$ Human papillomavirus; $\mathrm{SD}=$ standard deviation

4-point response scale ranging from "no chance" to "high chance" (coded 1-4).

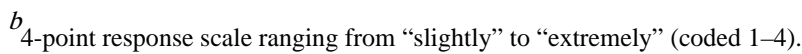

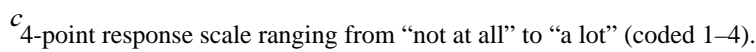

$d_{3}$ item scale, each item had a - point response scale ranging from "strongly disagree" to "strongly agree" (coded 1-4).

$e_{6}$ item scale, each item had a 4 point response scale ranging from "strongly disagree" to "strongly agree" (coded 1-4).

$f_{5}$ item scale, each item had a 3-point response scale "not hard at all" (coded as 1), "somewhat hard" (coded as 2.5), and "very hard (coded as 4), except for 1 item except for 1 item which used a 4-point response scale ranging from "strongly disagree" (to "strongly agree" (coded 1-4).

$g_{2}$ item scale, each item had a 4- point response scale ranging from "slightly effective" to "extremely effective" (coded 1-4).

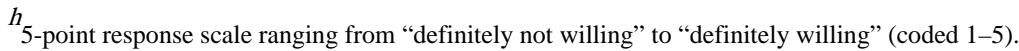

*

$p<0.05$,

*** $p<0.001$ 
Table 4

Past Internet use as a correlate of HPV vaccine attitudes and beliefs among parents of sons (HIS), $\underline{n=115}$

\begin{tabular}{|c|c|c|c|}
\hline & $\begin{array}{c}\text { No } \\
\text { Mean (SD) }\end{array}$ & $\begin{array}{c}\text { Yes } \\
\text { Mean (SD) }\end{array}$ & $\begin{array}{c}\text { Multivariate } \\
\beta\end{array}$ \\
\hline Perceived likelihood of HPV if child does not receive HPV vaccine ${ }^{a}$ & $2.27(0.64)$ & $2.18(0.64)$ & -0.05 \\
\hline Perceived likelihood of HPV if child receives HPV vaccine & -- & -- & -- \\
\hline Perceived severity & -- & -- & -- \\
\hline Anticipated regret if child receives HPV vaccine $b$ & $2.54(1.08)$ & $2.47(1.17)$ & 0.004 \\
\hline Anticipated regret if child does not receive HPV vaccine $b$ & $3.11(1.09)$ & $2.89(1.10)$ & -0.10 \\
\hline Uncertainty about HPV vaccine $e^{c}$ & $3.37(0.78)$ & $3.43(0.85)$ & -0.07 \\
\hline Perceived harms of HPV vaccine ${ }^{d}$ & $2.96(0.55)$ & $3.11(0.76)$ & 0.11 \\
\hline Perceived barriers to getting child ${ }^{e}$ HPV vaccine & $1.15(0.32)$ & $1.37(0.50)$ & $0.23^{*}$ \\
\hline Perceived effectiveness of $\mathrm{HPV}^{f}$ vaccine & $2.50(1.01)$ & $2.26(1.10)$ & -0.11 \\
\hline Willingness to get child vaccinated against HPV $g$ & $3.39(1.20)$ & $2.76(1.14)$ & -0.09 \\
\hline
\end{tabular}

Note. $\beta$ s represent standardized beta coefficients from multivariate models controlling for parent gender, age, race/ethnicity, education, household income, urbanicity, and child's age which were associated with HPV vaccine knowledge, attitudes, beliefs, or intentions in bivariate analyses ( $p<$. 05). Dashes (--) indicate that the item was not assessed. HPV= Human papillomavirus; SD= standard deviation.

a-point response scale ranging from "no chance" to "high chance" (coded 1-4).

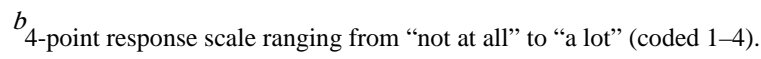

$c_{3}$ item scale, each item had a 5-point response scale ranging from "strongly disagree" to "strongly agree" (coded 1-5).

$d_{5}$ item scale, each item had a 5-point response scale ranging from "strongly disagree" to "strongly agree" (coded 1-5).

$e_{2}$ item scale, each item had a 3-point response scale ranging from "not hard at all" to "very hard", coded 1-3).

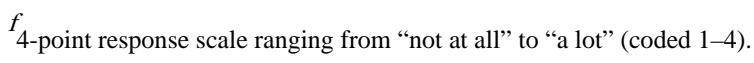

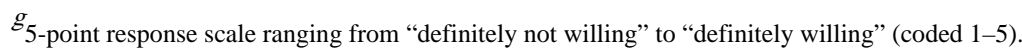

* $p<0.05$,

*** $p<0.001$ 


\section{Table 5}

Correlates of future HPV vaccine information-seeking on the Internet among parents of daughters (CHIME), $n=733$

\begin{tabular}{lcccc}
\hline & \multicolumn{2}{l}{ Internet as a future information source } & \\
\cline { 2 - 3 } & $\begin{array}{c}\text { No } \\
\text { mean (SD) }\end{array}$ & $\begin{array}{c}\text { Yes } \\
\text { mean (SD) }\end{array}$ & $\begin{array}{c}\text { Multivariate } \\
\text { OR (95\% CI) }\end{array}$ \\
\hline HPV knowledge $^{a}$ & $0.58(0.19)$ & $0.60(0.20)$ & $1.20(0.53-2.73)$ \\
Perceived likelihood of HPV if child does not receive HPV vaccine & $2.53(0.75)$ & $2.51(0.69)$ & $0.98(0.77-1.24)$ \\
Perceived likelihood of HPV if child receives HPV vaccine & $2.12(0.56)$ & $2.01(0.51)$ & $0.67(0.48-0.92)$ \\
Perceived severity of cervical cancer & $\underline{3.69(0.62)}$ & $\underline{3.72(0.55)}$ & $\underline{1.00(0.78-1.28)}$ \\
Anticipated regret if child receives HPV vaccine & $2.72(1.27)$ & $2.59(1.25)$ & $0.94(0.83-1.06)$ \\
Anticipated regret if child does not receive HPV vaccine & $3.57(0.81)$ & $3.66(0.73)$ & $1.18(0.95-1.48)$ \\
Uncertainty about HPV vaccine & $2.68(0.82)$ & $2.68(0.80)$ & $1.03(0.88-1.26)$ \\
Perceived harms of HPV vaccine & $2.17(0.60)$ & $2.13(0.52)$ & $0.88(0.66-1.18)$ \\
Perceived barriers to getting child HPV vaccine & $1.57(0.59)$ & $2.55(0.56)$ & $1.00(0.75-1.32)$ \\
Perceived effectiveness of HPV vaccine & $2.47(0.68)$ & $2.53(0.59)$ & $1.14(0.88-1.47)$ \\
Willingness to get child vaccinated against HPV & $2.75(0.88)$ & $2.78(0.96)$ & $1.08(0.92-1.27)$ \\
Doctor recommended HPV vaccine, $n(\%)$ & $\underline{62(27.19)}$ & $\underline{116(22.97)}$ & $\underline{0.73(0.51-1.06)}$ \\
\hline
\end{tabular}

Note. Table shows odds ratios from multivariate models controlling for parent race/ethnicity, education, and income which were associated with future Internet information-seeking in bivariate analyses $(p<.05)$. Response scales appear in Table 3.

$\mathrm{HPV}=$ Human papillomavirus; $\mathrm{SD}=$ standard deviation

a Proportion of correct responses to 5 items about HPV infection. Individual items were also examined and none were associated with future Internet information-seeking.

${ }^{*}<0.05$ 